\title{
REKAYASA VIDEO PROFILE SEBAGAI MEDIA PROMOSI STMIK SYAIKH ZAINUDDIN NW ANJANI MENGGUNAKAN TEKNIK VIDEOGRAFI
}

\author{
Yuliadi", Mahsun $^{2}$, Marzuki Adami ${ }^{3}$ \\ ${ }^{1}$ Teknik Informaika, Universitas Teknologi Sumbawa \\ ${ }^{2,3}$ Teknik Informatika, STMIK Syaikh Zaenuddin NW Anjani \\ yuliadi@uts.ac.id ${ }^{*}$
}

\begin{abstract}
Abstrak: Saat ini, persaingan dalam dunia pendidikan semakin ketat, oleh karena itu dibutuhkan strategi yang tepat dalam mencapai keberhasilan untuk meningkatkan kepeminatan calon mahasiswa. Dalam kegiatan promosinya belum menggunakan media hanya terbatas promosi dari mulut ke mulut antara jama'ah Nahdlatul Wathan yang hasilnya kurang lengkapnya informasi yang tersampaikan. Untuk mengatasi hal tersebut, penulis akan membuat media promosi dalam bentuk video profil dengan menggunakan teknik videografi yang dapat dimaanfatkan sebagai media promosi. Teknik ini sangat menarik dan inovatif sehingga mempunyai daya tarik tersendiri bagi yang melihatnya, video profil ini akan digunakan saat kunjungan sosialisasi kampus ke sekolah-sekolah serta dibagikan melalui media sosial. Video promosi unsur gerak, gambar, suara, dan juga musik yang menjelaskan secara detail mengenai profil, fasilitas, keunggulan, prestasi, kegiatan akademik dan kemahasiswaan serta metode pembelajaran. Dengan media tersebut bisa dijadikan sebagai sarana promosi untuk mengenalkan dan menyampiakan informasi STMIK Syaikh Zaenuddin NW Anjani.
\end{abstract}

Kata Kunci : Promosi, Nahdlatul Wathan, Video, Teknik Videografi, Media Promosi.

\begin{abstract}
Currently, competition in the world of education is getting tougher, therefore it takes the right strategy in achieving success to increase the interest of prospective students. In their promotional activities, they have not used the media, only limited word of mouth promotion between the Nahdlatul Wathan congregation which results in incomplete information conveyed. To overcome this, the author will create promotional media in the form of profile videos using videography techniques which can be used as promotional media. This technique is very interesting and innovative so that it has a special attraction for those who see it, this profile video will be used during campus socialization visits to schools and shared via social media. Promotional videos for elements of motion, pictures, sounds, and music that explain in detail about the profile, facilities, advantages, achievements, academic and student activities and learning methods. With this media, it can be used as a means of promotion to introduce and deliver STMIK information for Shaykh Zaenuddin NW Anjani.
\end{abstract}

Keywords : Promotion, Nahdlatul Wathan, Video, Videography Techniques, Media Promotion

\section{PENDAHULUAN}

Perkembangan teknologi dan informasi saat ini semakin pesat dengan berbagai macam media, pemanfaatan media promosi pada video profil memberikan daya tarik tersendiri, agar iklan sampai ke konsumen maka diperlukan media promosi yang jelas [1].

Jenis media promosi yang ada saat ini sangat bervariasi, hal tersebut dikarenakan tuntutan dari strategi promosi yang dikembangkan oleh perusahaan untuk mencapai profit untuk kemajuan sebuah Perusahaan. Promosi merupakan salah satu penentu keberhasilan suatu program pemasaran dalam suatu perusahaan [2].

Dalam memasarkan sebuah Jurusan di Perguruan Tinggi, membutuhkan media video promosi berupa media audio visual dengan durasi yang singkat namun dapat mempromosikan secara detail sehingga menjadi lebih menarik bagi konsumen. Sehingga dapat menjadi sarana efektif dalam menunjang kegiatan promosi dan informasi jurusan [3].

Sekolah Tinggi Manajemen Informatika dan Komputer (STMIK) Syaikh Zainuddin NW Anjani adalah perguruan tinggi swasta yang berada dibawah naungan pondok pesantren Syaikh Zainuddin Nahdlatul Wathan Anjani Lombok Timur Nusa
Tenggara Barat. Sebagai kampus IT dilihat dari usianya STMIK Syaikh Zaenuddin NW Anjani belum memiliki media informasi sarana promosi hanya sebatas mulut ke mulut jama'ah Nahdlatul Wathan dan penyebaran pamphlet ke sekolah-sekolah setiap tahun penerimaan mahasiswa baru.

Dengan penyebaran informasi melalui media promosi yang sudah biasa dilakukan kurang efektif, karena tidak bisa mengkover semua informasi yang terkait dari STMIK Syaikh Zaenuddin NW Anjani. Informasi yang disampaikan tidak hanya sebatas profil, sarana dan prasarananya tetapi mencakup keunggulan masing-masing program studi, prestasi dosen dan mahasiswa dala bidang akademik serta kemahasiswaan, aktivtas kegiatan kemahasiswaan dan lain sebagainya

Berdasakan permaslahan tersebut dibutuhkan sebuah media promosi berisi informasi yang berbentuk terkait informasi STMIK Syaikh Zaenuddin NW Anjani yang dapat dimanfaat Lembaga dalam memasarkan kampus yang lebih efektif.

\section{TINJAUAN PUSTAKA}

1. Tinjauan Pustaka 
Dalam penelitian ini, penulis merujuk pada beberapa penelitian yang sudah dilakukan diantarannya;

Pertama penelitian yang dilakukan oleh Fadhly Abdillah, Damar Adhiguna dan Agus Sevtiana dengan judul Perancangan Video Profile Sebagai Media Promosi STMIK CIC Dengan Tehnik Motion Graphic Menggunakan Perangkat Lunak Komputer Graphic. Penelitian ini bertujuan untuk membentuk media promosi dala bentuk video profil STMIK CIC dengan menggunakan teknik Motion Graphic dengan objek Flat Design. Teknik ini sangat menarik dan inovatif sehingga mempunyai daya tarik tersendiri bagi yang melihatnya, video profil ini akan digunakan saat kunjungan sosialisasi kampus ke sekolah-sekolah serta dibagikan melalui media sosial. Adobe After Effects, Adobe Media Encoder dan CorelDraw adalah Software untuk membuat teknik Motion Graphic itu sendiri dan Nuendo untuk perekam narasi [1].

Kedua penelitian yang dilakukan oleh Lusyani Sunarya, Nesya Elvina Ayudita dan Satria Agung Prabawa dengan judul Video Promosi Jurusan Sistem Informasi Berbasis Motion Graphic Pada STMIK Raharja Tangerang. Penelitia ini bertujuan untuk membuat video promosi berbasis motion graphic 2D yang mencakup unsur gerak, gambar, suara, dan juga musik yang menjelaskan secara detail mengenai profil jurusan Sistem Informasi STMIK Raharja, konsentasi yang ada di Jurusan Sistem Informasi, fasilitas, keunggulan, dan metode pembelajaran. Implementasi dari video promosi ini akan ditunjukan kepada calon mahasiswa/i baru yang berminat untuk mengambil jurusan Sistem Informasi dan sebagai media informasi dan promosi bagi masyarakat luas [3].

Ketiga penelitian yang dilakukan oleh Danang Rifai, Erna Astriyani dan Upi Indria dengan judul Pembuatan Video Company Profile Sebagai Penunjang Informasi dan Promosi Pada PT. Daiichi Elevator Indonesia. Penelitian ini bertujuan untuk media berbentuk video company profile sebagai penunjang informasi dan promosi serta dapat meningkatkan penjualan dan informasi kepada masyarakat yang ingin lebih tahu jelas mengenai liftl escalator di PT. Daiichi Elevator Indonesia agar lebih mengenal tentang detail profile yang dimiliki PT. Daiichi Elevator Indonesia [4].

2. Dasar Teori

a. Multimedia

Mmultimedia merupakan perpaduan antara berbagai media (format file) yang berupa teks, gambar ( vektor atau bitmap), grafik, sound, animasi, video, interaksi, dan lain-lain yang dikemas menjadi file digital (komputerisasi), digunakan untuk menyimpan atau menghatar pesan kepada publik [5].

b. Video Profile

Video adalah media audio visual yang menampilkan gambar dan suara. Pesan yang disajikan bisa berupa fakta (kejadian, peristiwa penting, berita) maupun fiktif (seperti misalnya cerita), bisa bersifat informatif, edukatif maupun instruksional. Company profile adalah produk tulisan praktisi yang berisi gambaran umum perusahaan. Gambaran ini tidak sepenuhnya lengkap, detail dan mendalam. Perusahaan atau lembaga bisa memilih poin-poin apa saja yang ingin disampaikan secara terbuka kepada publiknya. Video Profile merupakan media untuk memberikan citra positif perusahaan atau organisasi kepada klien prospek. Dalam tayangan audio visual ini, informasi tentang organisasi baik lingkup bisnis, etos organisasi, produktivitas, lingkungan organisasi, dan komitmen terhadap pelanggan dapat ditampilan secara lebih efektif melalui kombinasi shooting dengan narasi, keterangan teks, gambar ilustrasi serta animasi yang dapat menjelaskan suatu proses tertentu. Produktivitas dan harmoni kerja ditampilkan dengan gambar-gambar suatu proses kerja dengan iringan musik yang sesuai, sedangkan pelayanan terhadap pelanggan dapat digambarkan dengan senyumaan yang tulus dari para staf [6].

c. Media

Media adalah sarana untuk menyampaikan pesan atau informasi kepada publik dengan menggunakan berbagai unsur komunikasi grafis seperti teks atau gambar foto yang dikelompokkan menjadi lima macam adalah [7]:

1. Media cetak/visual (printed material), contohnya: poster (dalam dan luar), stiker, sampul buku, pembungkus, selipat (folder), selebaran (leaflet), amplop dan kop surat, tas belanja, katalog, iklan majalah dan surat kabar.

2. Media luar ruangan (outdoor), contohnya: spanduk (banner), papan nama, umbul-umbul, neon-box, neon-sign, billboard, baliho, mobile box.

3. Media elektronik (electronic), contohnya: radio, televisi, internet, film, program video, animasi komputer.

4. Tempat pajang (display), contohnya: etalase (window display), point of purchase, desain gantung, floor stand.

5. Barang-barang kenangan (special offer), contohnya: kaos, topi, payung, gelas, aneka souvenir, sajadah, tas dan sebagainya.

d. Media Informasi

Media informasi berupa media cetak mempunyai kelemahan, dilihat dari sisi effisiensi penyampaian informasi dan distribusi, namun bila menggunakan media informasi berupa Video Company Profile, informasi lebih efektif dan 
effisien, karena pengemasannya lebih menarik, dimana berupa file video yang menggabungkan beberapa format file, yaitu video, animasi dan suara, serta pengemasannya menggunakan media keping DVD sehingga lebih murah. Perancangan Video Profile Sebagai Media Pemasaran merupakan sebuah media informasi yang mengangkat tema media pemasaran produk, dimana perlunya sebuah media informasi yang efektif dan efisien untuk mendukung upaya promosi yang berisi informasi lengkap tentang perusahaan [8].

e. Media Promosi

Media promosi merupakan suatu alat untuk mengomunikasikan suatu produk perusahaan ataupun yang lain untuk dapat lebih dikenal masyarakat lebih luas. Secara umum media promosi dapat dikelompok menjadi ermpat kelompok yaitu media cetak, media elektronik, media luar ruang, dan media lini bawah [9].

f. Jenis-Jenis Media

Berikut jenis-jenis media promosi yang digunakan promosi adalah [10]:

1. Above The Line (Media Lini Atas), Above the line merupakan media promosi yang proses distribusinya biasanya menggunakan jasa biro periklanan sehingga perusahaan perlu menyiapkan budgeting/anggaran khusus.

2. Below The Line (Media Lini Bawah), Below the line adalah media periklanan yang distribusinya dilakukan tanpa menggunakan jasa periklanan. Sehingga perusahaan tidak memerlukan budgeting khusus.

g. Teknik Videografi

Videografi adalah media untuk merekam suatu moment/kejadian yang dirangkum dalam sebuah sajian gambar dan suara yang dapat kita nikmati dikemudian hari baik sebagai sebuah kenangan ataupun sebagai bahan kajian untuk mempelajari apa yang sudah/pernah terjadi. Videografi sendiri banyak digunakan oleh berbagai kalangan untuk berbagai kepentingan. Mulai dari individu hingga kelompok. Bahkan setiap negara dapat dipastikan memiliki arsip tentang sejarah negaranya yang berupa video. Seiring dengan perkembangan jaman dan dengan memanfaatkan kecanggihan teknologi terkini videografi dapat dinikmati dengan berbagai cara dan berbagai format pun ditawarkan oleh para ahli teknologi di dunia. Saat ini ada 2 jenis video yang teredia yaitu analog dan digital [11].

\section{METODE}

\section{Objek Penelitian}

Penelitian ini dilaksanakan di STMIK Stmik Syaikh Zainuddin NW Anjani yang beralamat di JL. Raya Mataram Labuhan Lombok KM 49 Pondok Pesantren Syaikh Zainuddin NW Anjan. Anjani,
Selong, Kabupaten Lombok Timur, Nusa Tenggara Barat 8361.

2. Teknik Pengumpulan Data

Dalam pengumpulan data dalam penelitian ini penulis menggunakan tahap Observasi, Wawancara dan Studi Pustaka.

3. Perancangan Media Video Promosi

Perancangan media video promosi melalui beberapa tahapan perancangan agar mendapatkan suatu gambaran tentang produk yang akan dibuat agar memudahkan dalam pembuatan video promosi. Tahapan yang dilakukan yaitu Preproduction, Production, dan Postproduction

\section{HASIL DAN PEMBAHASAN}

Berikut tampila video profil STMIK Syaikh Zainuddin NW Anjani yang diunakans sebagai media promosi adalah:

\section{Tampilan Intro}

Tampilan intro merupakan tampilan awal yang akan tampil ketika baru membuka video profil STMIK Syaikh Zainuddin NW Anjani, yakni:

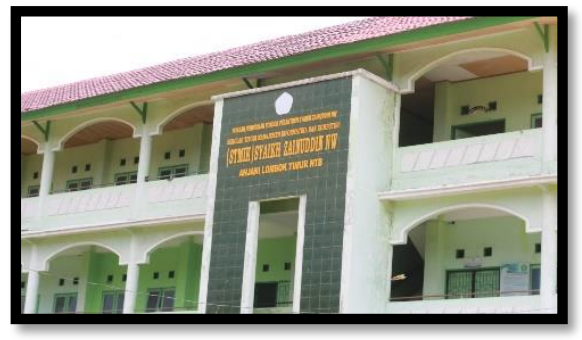

Gambar 2. Tampilan Intro Video Profile STMIK Syaikh Zainuddin NW Anjani

2. Tampilan Video Profile

Tampilan Video Profile merupakan tampilan video profil STMIK Syaikh Zainuddin NW Anjani, yakni:

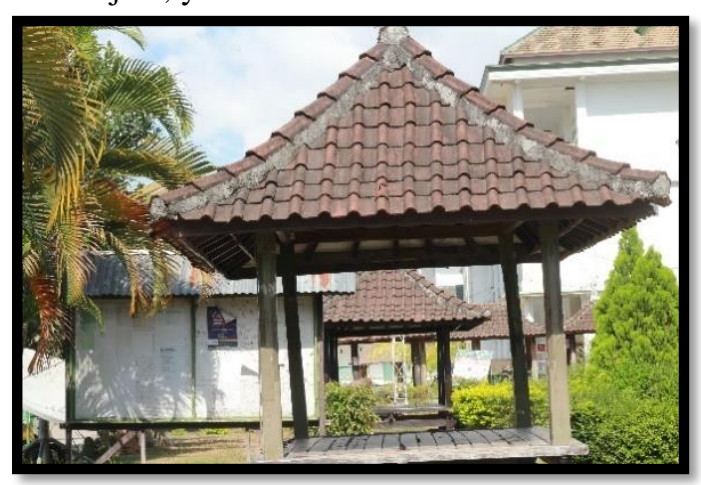

Gambar 3. Tampilan Video Profile STMIK Syaikh Zainuddin NW Anjani 
3. Tampilan Visi Misi

Tampilan Visi Misi merupakan tampilan terkait dengan visi misi STMIK Syaikh Zainuddin NW Anjani, yakni:

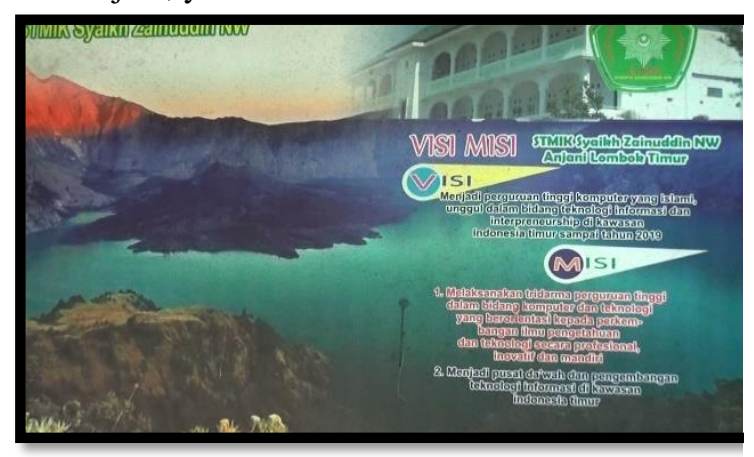

Gambar 4. Tampilan Visi Misi STMIK Syaikh Zainuddin NW Anjani

\section{KESIMPULAN DAN SARAN}

Media penyampaian informasi yang dibutuhkan STMIK Syaikh Zaenuddi NW Anjani sebagai sarana promosi ditunjukan kepada calon mahasiswa baru. Video Profile ini mencakup unsur gerak, gambar, suara, dan juga musik yang menjelaskan secara detail mengenai profil STMIK Syaikh Zaenuddin NW Anjani, konsentrasi yang ada pada Program Studi, fasilitas, keunggulan, prestasi dan metode pembelajaran. Strategi promosi yang dilakukan yaitu : video promosi akan di tayangkan pada saat agenda besar HULTAH NW, Presentasi internal oleh bagian Penerimaan Mahasis Baru, Presentasi ke sekolah-sekolah SMA/SMK, dan berbagai kegiatan promosi lainnya dalam upaya meningkatkan angka pendaftaran mahasiswa baru.

Melalui media video promosi STMIK Syaikh Zaenuddi NW Anjani ini diharapkanakan mencapai target pencapaian calon mahasiswa baru pada semua Program Studi setiap tahunnya, dan masyarakat lebih mengenal dan mengetahui informasi mengenai STMIK Syaikh Zaenuddi NW Anjani.

Dengan Media Promosi ini diharapkan STMIK Syaikh Zainuddin NW mampu memanfaatkan video profile yang dilengkapi dengan gambar/video ini digunakan dengan maksimal dalam melakukan promosi untuk meningkatkan minat calon mahasiswa/i baru untuk masuk. Selanjutnya bagi para pembaca, penulis menyarankan agar dapat mengembangkan video profil yang penulis rancang ini menjadi video profil yang lebih sempurna dan lebih luas cakupannya.

\section{DAFTAR PUSTAKA}

[1] Abdillah, Fadhly, D. Adhiguna, and A. Sevtiana, "Perancangan Video Profile Sebagai Media Promosi STMIK CIC Dengan Tehnik Motion Graphic,” J. Digit, vol. 7, no. 1, pp. 74-85, 2017, [Online].

Available:
https://jurnaldigit.org/index.php/DIGIT/article/vie wFile/17/18.

[2] Maimunah, L. Sunarya, and Nina Larasati, "Media Company Profile Sebagai Sarana Penunjang Informasi dan Promosi," vol. 5, no. 40, pp. 281301, 2012, [Online]. Available: http://ejournal.raharja.ac.id/index.php/ccit/article/ view/155/116.

[3] L. Sunarya, N. E. Ayudita, and S. A. Prabawa, "Video Promosi Jurusan Sistem Informasi Berbasis Motion Graphic Pada STMIK Raharja Tangerang," vol. 4, no. 1, pp. 35-45, 2018, [Online]. Available: http://ejournal.raharja.ac.id/index.php/sensi/articl e/view/712/630.

[4] D. Rifai, E. Astriyani, and U. Indria, "Pembuatan Video Company Profile Sebagai Penunjang Informasi dan Promosi Pada PT. Daiichi Elevator Indonesia," Technomedia J., vol. 3, no. 1, pp. 98109, 2018, doi: 10.33050/tmj.v3i1.384.

[5] A. Kausar, Y. F. Sutiawan, and V. Rosalina, "Perancangan Video Company Profile Kota Serang Dengan Teknik Editing Menggunakan Adobe Premier Pro CS 5," J. PROSISKO, vol. 2, no. 1, 2015, [Online]. Available: https://ejurnal.lppmunsera.org/index.php/PROSISKO/arti cle/download/94/153/.

[6] R. Indrawan and A. Y. M. Tumimomor, "Perancangan Company Profile SMK Negeri 2 Salatiga Menggunakan Teknik Motion Tracking," no. 692013023, 2018, [Online]. Available: https://repository.uksw.edu/bitstream/123456789/ 17174/2/T1_692013023_Full text.pdf.

[7] Ardiyan Indra Saputra, "Perancangan Media Promosi Denaro Pizza dan Resto Yogyakarta," Universitas Negeri Yogyakarta, 2013.

[8] T. Haryanto and S. Nugroho, "Perancangan Video Company Profile Sebagai Media Promosi Perusahaan Pada PT. Propan Raya ICC Semarang Tri," J. Ilm., vol. 8, no. 1, pp. 46-52, 2015, [Online]. Available: https://jurnal.stekom.ac.id/index.php/pixel/article/ view/39/38

[9] B. Nor, "Media Promosi Pemasaran," 2020. https://www.bahyudinnor.com/2020/01/mediapromosi-pemasaran.html.

[10] T. Siddiq, "Perancangan Media Promosi Internatinal Batik Center Pekalongan," Universitas Negeri Semarang, 2014

[11] Anonymous, "Pengertian Videografi dan Tekniknya," 2016. http://agusman1.blogspot.com/2016/07/pengertia n-videografi-sebelum-kita.html. 